\title{
Principales Retos de la Economía Mundial: Raíces Económicas del deterioro ecológico y social( 1 ) y alternativas en construcción. Un modelo de aprendizaje basado en problemas
}

\section{Main challenges of the world economy: Economic roots of the social and ecological deterioration and alternatives in construction. A problem- based learning model}

CAROLINA MÁrQUez GUERRERO

ORCID: https://orcid.org/0000-0002-4729-2480

Universidad de Sevilla

Departamento de Economía Aplicada II carolina@us.es

DOI: http://dx.doi.org/10.12795/9788447221912.040

Pp.: 909-932

1 Título tomado del libro de J.M. Naredo: "Las raíces económicas del deterioro ecológico y social" S.XXI 


\section{Resumen}

La presente comunicación está basada en el Ciclo de Mejora Docente (CMD) diseñado, experimentado y evaluado durante el curso académico 2018-19 en el marco de la Red de Formación e Innovación Docente (REFID) de la Universidad de Sevilla. Este CMD se aplicó al conjunto de la asignatura “Economía Mundial", de 2ºcurso, del Grado de Economía². La innovación docente ha consistido en la aplicación de un modelo de aprendizaje basado en problemas. La asignatura se ha estructurado en ocho bloques (mitos económicos) que los alumnos, guiados por la docente, han debido investigar. Esta enseñanza pone al estudiante en el centro de la escena y le responsabiliza de su propio aprendizaje. Los resultados han sido extraordinarios. La mayoría de los alumnos considera que "la asignatura ha cambiado profundamente su manera de ver la realidad".

Palabras clave: Economía mundial, Grado de Economía, docencia universitaria, Experimentación docente universitaria, Aprendizaje basado en problemas

\section{Abstract}

The present communication is based on the Cycle of Educational Improvement (CMD) designed, experienced and evaluated during the academic course 2018-19 within the framework of the Network of Training and Teaching Innovation (REFID) of the University of Seville. This CMD is applied to the whole of the subject "World economy", 2nd course, Degree of Economy. Teaching innovation consisted in the application of a problem-based learning model. The course is structured into eight blocks (economic myths) that the students, guided by the teacher, have due investigate. This teaching puts the student in the middle of the scene and make them responsible for their own learning. The results have been extraordinary. The majority of students considered that "the subject has changed deeply their way of seeing reality".

Key words: World Economics, Economy grade, University teaching, University teaching experimentation, Problem-based learning

\footnotetext{
2 Tres grupos, 45 alumnos por grupo, y durante un período de 10 semanas lectivas
}

Jornadas de Formación e Innovación Docente del Profesorado | № 2 (2019) Esta obra se distribuye con la licencia Creative Commons 


\section{Contexto}

Una elevada proporción de los estudiantes que cursan esta asignatura no están, aparentemente, muy motivados. Han sido educados, según sus palabras, para "vomitar" unos "conocimientos" previamente "engullidos". Son jóvenes a los que se les ha enseñado a obedecer (Trainer, T. 2017) y, por lo general, cumplen sin discusión las normas impuestas. Su preocupación central es su futura empleabilidad, en un contexto socioeconómico en el que el trabajo se ha convertido en un bien escaso; casi un lujo.

Llegan a la Universidad esperando un cambio radical en su experiencia previa, y se encuentran, por lo general, con un panorama similar: enseñanzas bulímicas y "enciclopédicas", horas y horas escuchando clases magistrales, limitada actividad crítica y de análisis, etc. Este tipo de enseñanza no les sirve ni para conectar con ellos mismos, ni para conectar con el grupo ni para conectar con la realidad. Esto es particularmente cierto en el ámbito de la economía, una ciencia que en su versión más ortodoxa (la dominante) sufre de un autismo agudo respecto a la realidad social, por no hablar del ensalzamiento de la competencia y del egoísmo como vías preferentes para alcanzar el bienestar social.

En cuanto a los profesores, no hemos recibido de manera obligatoria formación pedagógica alguna, lo que se agrava con un sesgo clarísimo en nuestras universidades hacia la investigación. La docencia está devaluada en el quehacer universitario, y cuanto más bajo es el curso (primeros y segundos de Grado) más devaluada está. Se da por supuesto que el buen investigador tiene necesariamente que ser un buen docente cuando esto es bastante inexacto ya que lo primero no implica que se tengan las necesarias aptitudes y actitudes para ser un buen educador. Entre los docentes, también existe una gran presión y preocupación por su empleabilidad. 


\section{Diseño previo del CMD}

La asignatura está planteada como un proyecto de investigación cuyo hilo conductor es el siguiente (Figura 1): La economía mundial se encuentra en la actualidad inmersa en una crisis que podríamos definir como civilizatoria, y que lleva dentro de sí, múltiples crisis: el colapso ecológico; el agotamiento de los combustibles fósiles; la pobreza y la desigualdad; y el reto demográfico, entre otros. En la raíz de esta insostenibilidad ecológica y social se encuentra un Sistema Económico que pretende alcanzar su estabilidad mediante la perpetuación de un crecimiento económico infinito -sobre un planeta finito-, y en un Sistema Político cuyo objetivo último es el mantenimiento de dicho modelo de acumulación. El resultado es una crisis socioambiental sin precedentes en la historia humana.

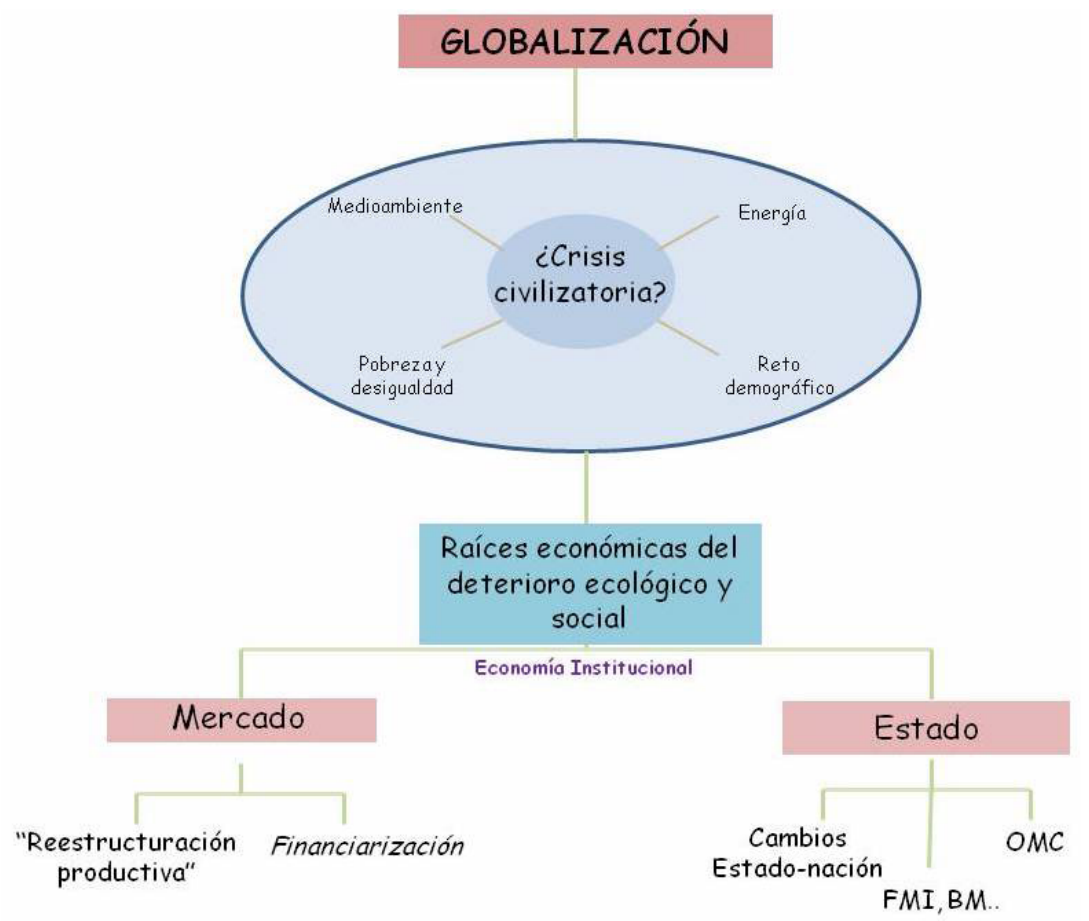

Figura 1. Mapa de contenidos de la asignatura Economía Mundial

Jornadas de Formación e Innovación Docente del Profesorado I № 2 (2019) Esta obra se distribuye con la licencia Creative Commons Reconocimiento-NoComercial-SinObraDerivada 
A partir de esta hipótesis inicial, el curso se articula en torno al análisis de ocho mitos: 1) La posibilidad de un crecimiento económico infinito sobre un planeta finito; 2) La infinitud de recursos naturales y la perfecta sustituibilidad de los mismos; 3) la posibilidad de extender a escala planetaria el modelo de desarrollo "euroaltántico"; 4) "Nos están invadiendo" (los movimientos migratorios); 5) Las empresas transnacionales: principales agentes creadores de riqueza y bienestar; 6) El sistema financiero: al servicio de la generación de riqueza; 7) El Estado frente al mercado; y 8) El libre comercio. Las Figuras 2-7 representan los mapas conceptuales (hojas de ruta) para estudiar cada uno de los mitos económicos que han sido investigados en el marco de este $\mathrm{CMD}^{3}$.

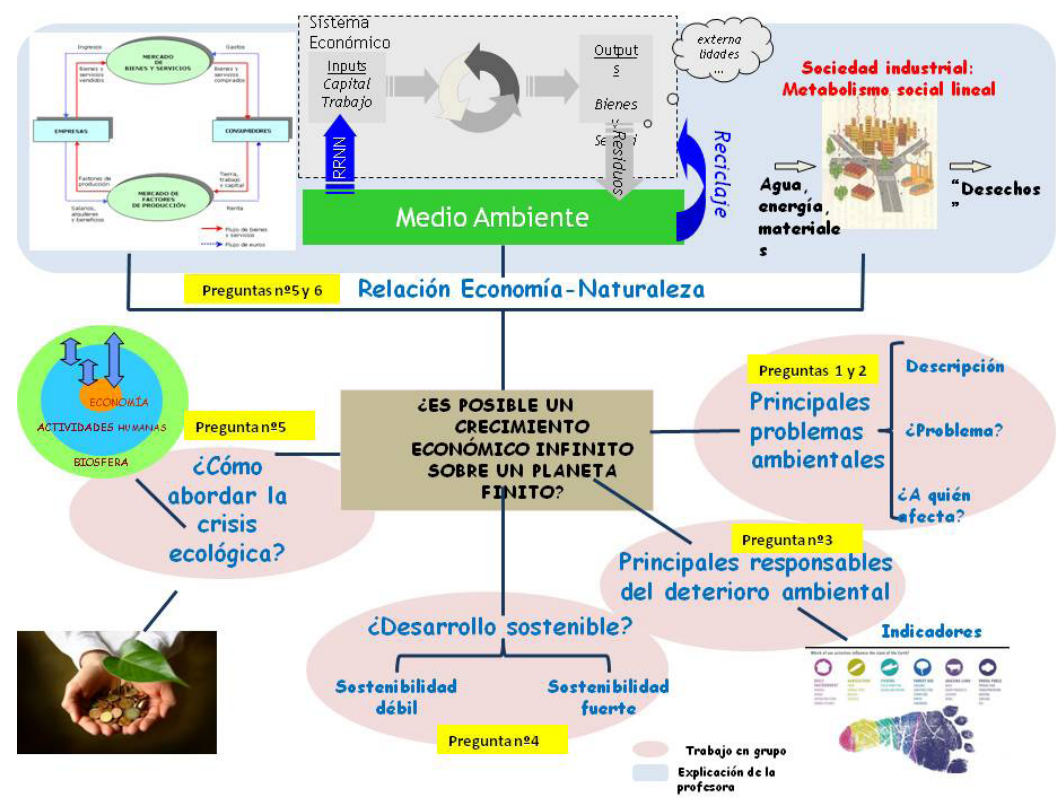

Figura 2. Mapa de contenidos del reto ambiental

3 "El sistema financiero: al servicio de la generación de riqueza"; y “El Estado frente al mercado"; no están incluidos en este CMD.

Jornadas de Formación e Innovación Docente del Profesorado | № 2 (2019) Esta obra se distribuye con la licencia Creative Commons Reconocimiento-NoComercial-SinObraDerivada 


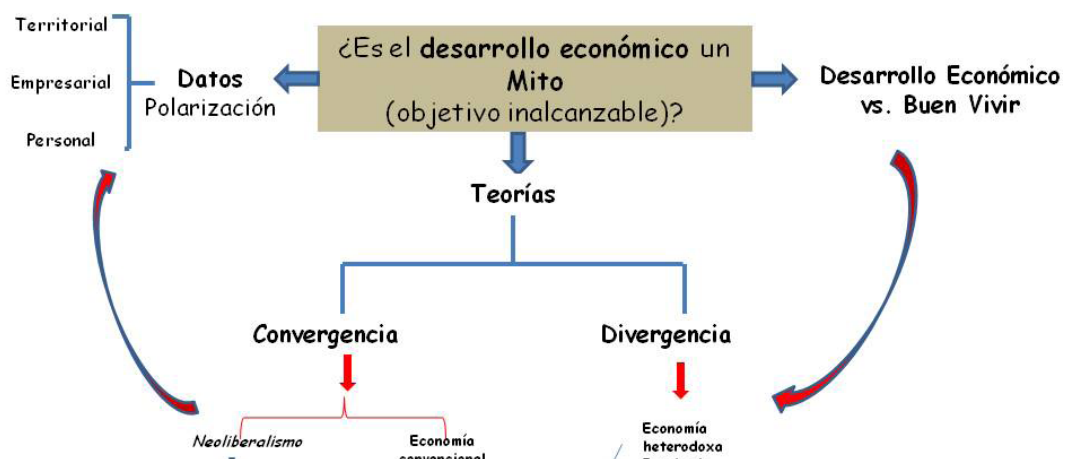

Figura 3. Mapa de contenidos del reto energético

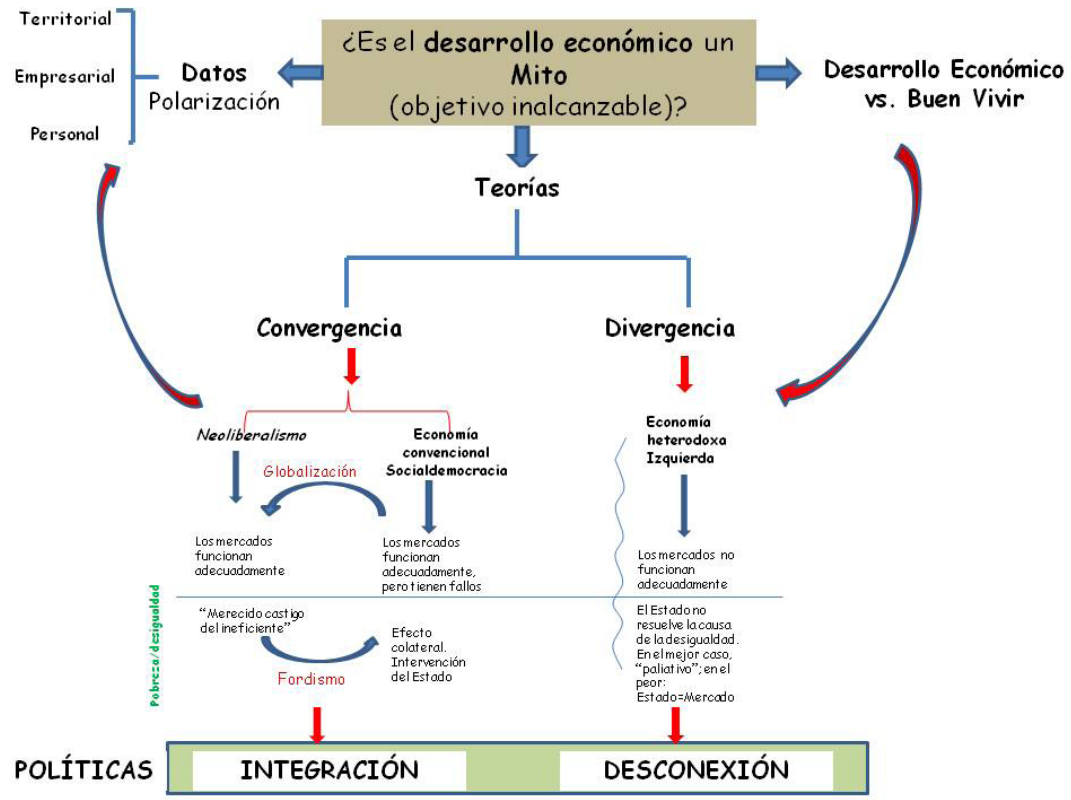

Figura 4. Mapa de contenidos del mito del desarrollo económico al modo euroatlántico

Jornadas de Formación e Innovación Docente del Profesorado | № 2 (2019) Esta obra se distribuye con la licencia Creative Commons Reconocimiento-NoComercial-SinObraDerivada 


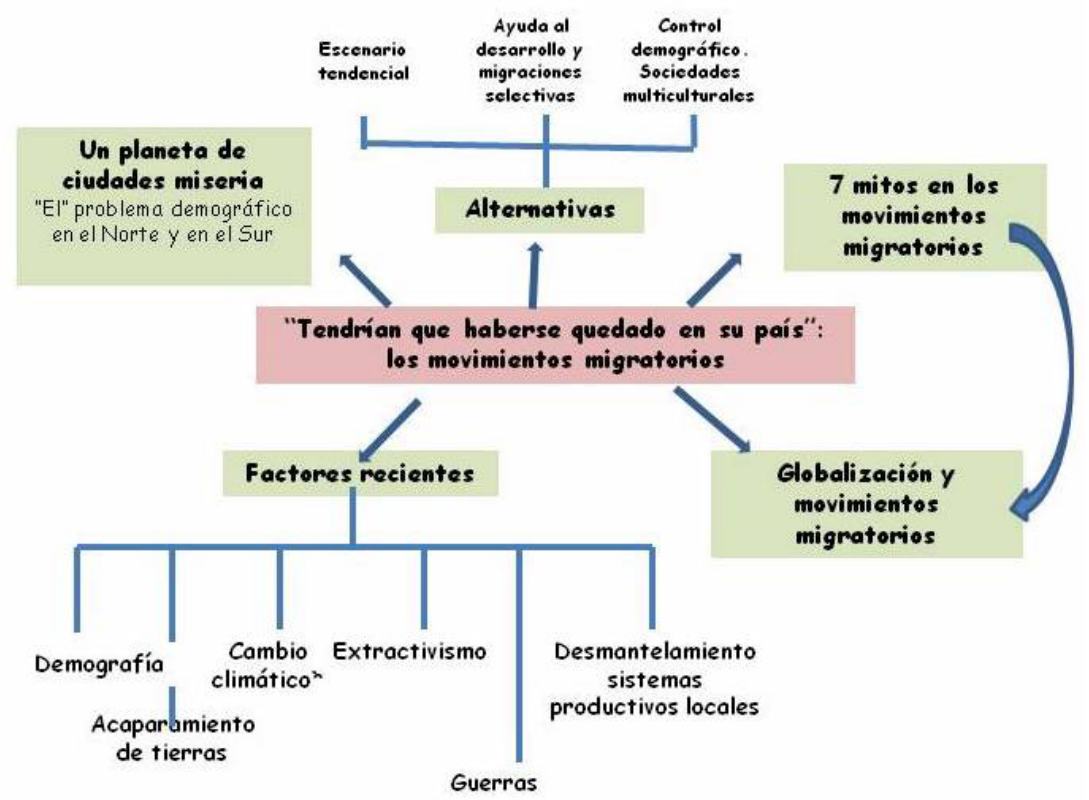

Figura 5. Mapa de contenidos del reto demográfico

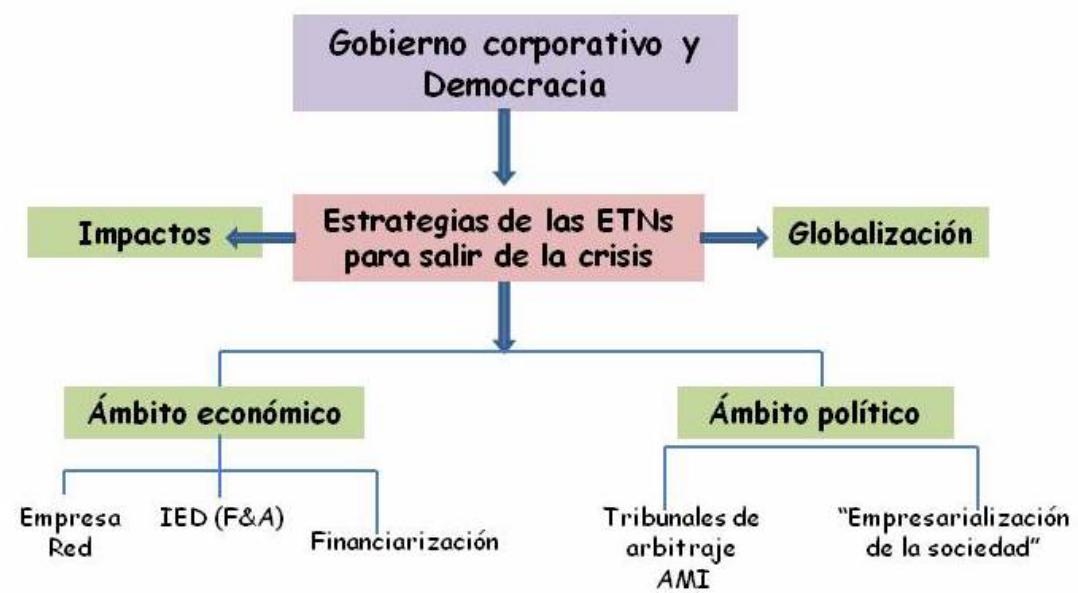

Figura 6. Mapa de contenidos del papel de las empresas transnacionales

Jornadas de Formación e Innovación Docente del Profesorado | № 2 (2019) Esta obra se distribuye con la licencia Creative Commons Reconocimiento-NoComercial-SinObraDerivada Internacional (CC BY-NC-ND 4.0.) 


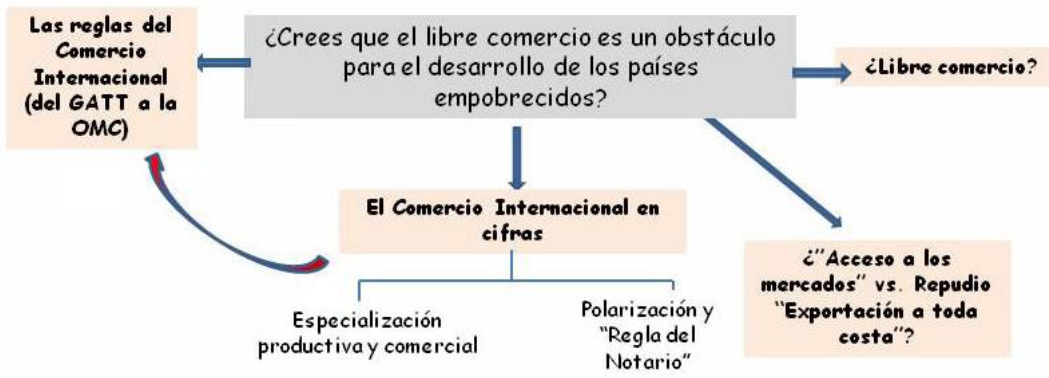

Figura 7. Mapa de contenidos del mito del Libre Comercio

\section{Modelo metodológico}

El modelo metodológico aplicado consta de tres fases: a) Análisis de los modelos mentales de I@s alumn@s a través de un cuestionario inicial relacionado con el problema/tema central que vamos a trabajar; b) Realización de las "actividades de contraste" (proceso de indagación / investigación); y c) Valoración del aprendizaje a partir del cuestionario final (inicial). En este, l@s estudiantes explican cual era su idea inicial del problema, qué piensan después de haberlo trabajado y las razones que le han llevado a cambiar (si es que ha habido un cambio) su perspectiva/ entendimiento del problema.

Jornadas de Formación e Innovación Docente del Profesorado | № 2 (2019) Esta obra se distribuye con la licencia Creative Commons Reconocimiento-NoComercial-SinObraDerivada 


\section{Aplicación real del CMD}

A continuación se muestran los cuestionarios iniciales/finales y las actividades de "contraste" correspondientes a los distintos mitos económicos finalmente trabajados en este $C M D^{4}$ :

Tabla 1. El Reto ambiental

\begin{tabular}{|c|c|}
\hline Cuestionario & Actividad de contraste \\
\hline $\begin{array}{l}\text { ¿Cuáles crees que son los } \\
\text { principales problemas ecológicos } \\
\text { hoy en día? ¿Existe alguna relación } \\
\text { entre ellos? Razona tu respuesta }\end{array}$ & $\begin{array}{l}\text { Video: "La historia de las cosas" } \\
\text { https://www.youtube.com/ } \\
\text { watch?v=ASoC231fE0U } \\
\text { Explicación en clase: metabolismo } \\
\text { socioeconómico lineal }\end{array}$ \\
\hline $\begin{array}{l}\text { ¿En qué medida son un problema } \\
\text { (gravedad)? ¿A quienes afecta } \\
\text { principalmente? }\end{array}$ & $\begin{array}{l}\text { Explicación en clase: principales } \\
\text { damnificados de la crisis ambiental }\end{array}$ \\
\hline $\begin{array}{l}\text { ¿Quiénes son los principales } \\
\text { responsables del deterioro } \\
\text { ambiental? Razona tu respuesta } \\
\text { (indicador/res) }\end{array}$ & $\begin{array}{l}\text { Grupos de } 5 \text { estudiantes: análisis } \\
\text { de Huella ecológica e informe con } \\
\text { conclusiones }\end{array}$ \\
\hline $\begin{array}{l}\text { ¿Qué entiendes por "Desarrollo } \\
\text { Sostenible"? ¿Cómo se puede medir } \\
\text { la sostenibilidad? }\end{array}$ & $\begin{array}{l}\text { Seminario/debate sobre la lectura } \\
\text { J.M. Naredo: "Sobre el origen, el } \\
\text { uso y el contenido del término } \\
\text { sostenible" http://habitat.aq.upm. } \\
\text { es/cs/p2/a004.html }\end{array}$ \\
\hline $\begin{array}{l}\text { ¿Qué respuestas - desde la } \\
\text { economía- crees que se están } \\
\text { dando para abordar la crisis } \\
\text { ambiental? ¿Crees que son } \\
\text { suficientes? ¿Porqué? }\end{array}$ & $\begin{array}{l}\text { Explicación en clase: enfoques } \\
\text { alternativos para abordar la crisis } \\
\text { ambiental }\end{array}$ \\
\hline $\begin{array}{l}\text { ¿Crees que es posible un } \\
\text { crecimiento económico infinito } \\
\text { sobre un planeta finito? Razona tu } \\
\text { respuesta }\end{array}$ & Conclusión y cierre \\
\hline
\end{tabular}

$4 \quad$ A demanda de los alumnos, se acortaron dos de los "temas": la financiarización de la economía y el papel del Estado en la Globalización, con el objetivo de que se pudieran trabajar en clase la Alternativas al actual modelo socioeconómico. Estas actividades -Alternativas- no están incluidas en el CMD presentado en esta comunicación.

Jornadas de Formación e Innovación Docente del Profesorado | № 2 (2019) Esta obra se distribuye con la licencia Creative Commons Reconocimiento-NoComercial-SinObraDerivada Internacional (CC BY-NC-ND 4.0.) 


\begin{tabular}{|l|l|}
\hline \multicolumn{1}{|c|}{ Cuestionario } & \multicolumn{1}{c|}{ Actividad de contraste } \\
\hline $\begin{array}{l}\text { ¿Cómo sería nuestra vida sin } \\
\text { combustibles fósiles? } \\
\text { ¿Qué es el "Pico del petróleo"? }\end{array}$ & $\begin{array}{l}\text { Videos Crash course (17ä y 17b) y A. } \\
\text { Turiel https:/ www.youtube.com/ } \\
\text { watch?v=A1sCx7e6tmY }\end{array}$ \\
\hline $\begin{array}{l}\text { Análisis/debate } \\
\text { ¿Cómo debería llevarse a cabo, } \\
\text { transición energética? Razona tu } \\
\text { respuesta }\end{array}$ & $\begin{array}{l}\text { Seminario/debate sobre el texto } \\
\text { VVAA (2019) "Soberanía energética" }\end{array}$ \\
\hline $\begin{array}{l}\text { ¿Crees que hay alguna relación } \\
\text { entre energía y equidad? Es decir } \\
\text { ¿existe una dimensión político- } \\
\text { social/distributiva en el "problema } \\
\text { energético"? }\end{array}$ & $\begin{array}{l}\text { Explicación en clase: energía y } \\
\text { equidad. Algunos datos a nivel } \\
\text { mundial }\end{array}$ \\
\hline $\begin{array}{l}\text { ¿Qué Alternativas crees que existen } \\
\text { al actual modelo energético? }\end{array}$ & Debate en clase y cierre \\
\hline
\end{tabular}

\section{Tabla 3. El mito del desarrollo económico al modo euroatlántico}

\begin{tabular}{|l|l|}
\hline \multicolumn{1}{|c|}{ Cuestionario } & \multicolumn{1}{c|}{ Actividad de contraste } \\
\hline $\begin{array}{l}\text { ¿Qué es para ti el desarrollo } \\
\text { económico? ¿Crees que es un } \\
\text { concepto universal; que todo el } \\
\text { mundo entiende lo mismo por } \\
\text { "desarrollo económico"? }\end{array}$ & $\begin{array}{l}\text { Video "What the Health" } \\
\text { https://WwW.youtube.com/ }\end{array}$ \\
\hline $\begin{array}{l}\text { ¿Crees que el desarrollo económich-RKfXM8M } \\
\text { es un mito, un objetivo inalcanzable } \\
\text { para la mayoría de los países? } \\
\text { Razona tu respuesta }\end{array}$ & $\begin{array}{l}\text { Seminario/debate sobre el } \\
\text { texto Sachs, W. "Globlización, } \\
\text { convergencia y modelo de } \\
\text { desarrollo euroatlántico" }\end{array}$ \\
\hline $\begin{array}{l}\text { ¿Cómo lo medirías? ¿Qué } \\
\text { indicadores utilizarías? }\end{array}$ & Explicación en clase: El PIB \\
\hline $\begin{array}{l}\text { ¿Qué tendrían que hacer los } \\
\text { países para alcanzar el desarrollo } \\
\text { económico? ¿Cuáles crees que } \\
\text { son los principales obstáculos } \\
\text { que tienen los países pobres para } \\
\text { alcanzar el desarrollo económico? }\end{array}$ & $\begin{array}{l}\text { Explicación en clase: Teorias } \\
\text { económicas de la convergencia y de } \\
\text { la divergencia } \\
\text { Debate en clase y cierre }\end{array}$ \\
\hline
\end{tabular}

Jornadas de Formación e Innovación Docente del Profesorado | № 2 (2019) Esta obra se distribuye con la licencia Creative Commons Reconocimiento-NoComercial-SinObraDerivada Internacional (CC BY-NC-ND 4.0.) 
Tabla 4. El Reto demográfico

\begin{tabular}{|c|c|}
\hline Cuestionario & Actividad de contraste \\
\hline $\begin{array}{l}\text { ¿Crees que los países ricos deben } \\
\text { poner fronteras a los movimientos } \\
\text { migratorios? Razona tu respuesta }\end{array}$ & $\begin{array}{l}\text { Seminario/debate sobre el texto } \\
\text { Intermón Oxfam "Desmontando } \\
\text { mitos. Siete respuestas inteligentes } \\
\text { sobre la crisis de refugiados" }\end{array}$ \\
\hline $\begin{array}{l}\text { ¿Tienes idea de cómo han } \\
\text { evolucionado estos movimientos en } \\
\text { la globalización? ¿volumen? ¿Países } \\
\text { de origen y destino? ¿Perfil del } \\
\text { emigrante? }\end{array}$ & $\begin{array}{l}\text { Explicación en clase: Los } \\
\text { movimientos migratorios en la } \\
\text { globalización }\end{array}$ \\
\hline $\begin{array}{l}\text { ¿Qué factores crees que están detrás } \\
\text {-son causa- de los movimientos } \\
\text { migratorios internacionales } \\
\text { actualmente? Explícalos }\end{array}$ & $\begin{array}{l}\text { Lectura en clase/ debate texto } \\
\text { M.Delgado } \\
\text { Sintesis por parte de la profesora } \\
\text { factores desencadenantes } \\
\text { movimientos migratorios }\end{array}$ \\
\hline $\begin{array}{l}\text { ¿Cuál crees que el principal reto } \\
\text { demográfico a nivel mundial? ¿Es el } \\
\text { mismo en los países ricos que en los } \\
\text { países pobres? }\end{array}$ & $\begin{array}{l}\text { Explicación en clase: Un planeta de } \\
\text { ciudades miseria }\end{array}$ \\
\hline $\begin{array}{l}\text { ¿Qué soluciones crees que habría } \\
\text { que dar a este problema? Explica tu } \\
\text { respuesta }\end{array}$ & $\begin{array}{l}\text { Videos: Pacto Mundial para la } \\
\text { Migración https://www.youtube. } \\
\text { com/watch?v=XzTypC1jbll } \\
\text { https://www.youtube.com/ } \\
\text { watch?v=WROBTFCzvV8. } \\
\begin{array}{l}\text { Debate en clase (tres grupos) y } \\
\text { cierre }\end{array}\end{array}$ \\
\hline
\end{tabular}

Tabla 5. El papel de las Empresas Transnacionales (ETNs)

\begin{tabular}{|l|l|}
\hline \multicolumn{1}{|c|}{ Cuestionario } & \multicolumn{1}{c|}{ Actividad de contraste } \\
\hline ¿Qué es para ti la Globalización? & $\begin{array}{l}\text { Video: "La trastienda de Ikea" } \\
\text { https:/ / www.youtube.com/ }\end{array}$ \\
$\begin{array}{ll}\text { watch?V=LkpNL9VMkHI\&t=1177s } \\
\text { Análisis/debate }\end{array}$ \\
\hline $\begin{array}{l}\text { ¿Quiénes crees que son sus } \\
\text { principales “constructores"? Explica tu } \\
\text { respuesta }\end{array}$ & $\begin{array}{l}\text { Seminario/debate sobre el texto } \\
\text { de Van der Ploeg: “Imperios } \\
\text { alimentarios" (Parmalat) }\end{array}$ \\
\hline $\begin{array}{l}\text { Fecha de "nacimiento", objetivos e } \\
\text { "instrumentos" de la globalización }\end{array}$ & Explicación en clase \\
\hline
\end{tabular}

Jornadas de Formación e Innovación Docente del Profesorado | № 2 (2019) Esta obra se distribuye con la licencia Creative Commons Reconocimiento-NoComercial-SinObraDerivada Internacional (CC BY-NC-ND 4.0.) 
¿Crees que las empresas

transnacionales han tenido algún

papel en la construcción de la globalización? ¿Qué estrategias han utilizado en este período?

¿Qué repercusiones ha tenido y está teniendo la globalización?

¿Crees que son compatibles

Globalización y Democracia? Razona tus respuestas
Seminario/debate sobre los textos de Mazzucatto: "El Estado detrás del Iphone"; y "Sistemas Abiertos de Innovación"

Explicación en clase: síntesis estrategias ETNs

Lectura en clase, análisis y debate del texto: "Tribunales para atracar a los Estados" Le Monde Diplomatique Lectura en clase, análisis y debate del texto "La empresarialización de la sociedad"

Explicación en clase: Acuerdo Multilateral de Inversiones (AMI) y su incorporación en los Tratados de libre comercio, inversiones y en la OMC

\section{Tabla 6. El "Libre Comercio"}

\begin{tabular}{|l|l|}
\hline \multicolumn{1}{|c|}{ Cuestionario } & \multicolumn{1}{c|}{ Actividad de contraste } \\
\hline ¿Qué entiendes por libre comercio? & $\begin{array}{l}\text { Video: "La poderosa agricultura } \\
\text { europea" https://www.youtube. } \\
\text { com/watch?v=dgXPrnzCTTg\&t=8s } \\
\text { Análisis/debate }\end{array}$ \\
\hline $\begin{array}{l}\text { ¿Debería significar el libre comercio } \\
\text { ¿Qmpetir en igualdad de condiciones? } \\
\text { igualdad de condiciones? }\end{array}$ & Debate en clase \\
\hline $\begin{array}{l}\text { ¿Crees que actualmente, en la } \\
\text { globalización, existe el libre comercio? } \\
\text { Razona tu respuesta }\end{array}$ & \\
\hline $\begin{array}{l}\text { ¿Crees que el libre comercio tal y } \\
\text { como se entiende por la economía } \\
\text { convencional es un obstáculo para el } \\
\text { desarrollo de la mayor parte de los } \\
\text { países? Explica tu respuesta }\end{array}$ & $\begin{array}{l}\text { Seminario/debate en clase de los } \\
\text { textos de Intermón Oxfam: "Nuestro } \\
\text { futuro por la borda" y V. Shiva: } \\
\text { "Exportación a toda costa" }\end{array}$ \\
\hline $\begin{array}{l}\text { ¿Quién establece las reglas del } \\
\text { comercio internacional? ¿Existe } \\
\text { alguna institución encargada de esta } \\
\text { tarea? ¿Cuáles son estas reglas? }\end{array}$ & $\begin{array}{l}\text { Explicación en clase: "Del GATT a la } \\
\text { OMC" }\end{array}$ \\
\hline $\begin{array}{l}\text { ¿Existen Alternativas al "libre } \\
\text { comercio? ¿Cuáles conoces? }\end{array}$ & $\begin{array}{l}\text { Debate en clase (tres grupos: "libre } \\
\text { mercado"; "Acceso a los mercados" } \\
\text { "No a la exportación como } \\
\text { prioridad") y cierre }\end{array}$ \\
\hline
\end{tabular}




\section{Resultados del CMD}

Los resultados del CMD han sido extraordinarios. La mayoría de los alumnos considera que "la asignatura les ha cambiado profundamente su manera de ver la realidad". De los 136 alumnos que han seguido la evaluación continua, un 5,1\% la abandonaron antes de acabar el curso; $12,5 \%$ no han superado la evaluación continua; un 46,32\% han aprobado; un 33,7\% han obtenido un notable como calificación final; un 2,2,\% han alcanzado el sobresaliente y el resto -2,9\%- obtuvieron Matrícula de Honor.

A continuación se muestran algunas escaleras de aprendizaje extraídas de cuatro de los bloques temáticos trabajados durante la aplicación de este CMD.

Tabla 7. ¿Qué factores crees que están detrás de los movimientos migratorios internacionales en la actualidad?

\begin{tabular}{|l|c|l|c|}
\hline \multicolumn{1}{|c|}{ Respuestas } & $\begin{array}{c}\text { Cuestionario } \\
\text { inicial }\end{array}$ & \multicolumn{1}{|c|}{$\begin{array}{c}\text { Principales } \\
\text { obstáculos }\end{array}$} & $\begin{array}{c}\text { Cuestionario } \\
\text { final }\end{array}$ \\
\hline No sabe/no contesta & $16 \%$ & & $0 \%$ \\
\hline $\begin{array}{l}\text { Factores internos: } \\
\text { pobreza, guerras... }\end{array}$ & $53 \%$ & $\begin{array}{l}\text { "No es un } \\
\text { problema de los } \\
\text { países ricos" }\end{array}$ & $28 \%$ \\
\hline $\begin{array}{l}\text { Sistema Económico (en } \\
\text { general) }\end{array}$ & $22 \%$ & & $6 \%$ \\
\hline $\begin{array}{l}\text { Algunos factores } \\
\text { concretos sin } \\
\text { planteamiento acerca de } \\
\text { las raíces del problema }\end{array}$ & 0 & $\begin{array}{l}\text { Sequías, cambio } \\
\text { climático, etc.. } \\
\text { sin buscar } \\
\text { las raíces del } \\
\text { problema }\end{array}$ & $9 \%$ \\
\hline $\begin{array}{l}\text { Factores concretos } \\
\text { vinculados a las } \\
\text { relaciones Norte-Sur } \\
\text { y a las raíces de los } \\
\text { problemas: extractivismo, } \\
\text { acaparamiento } \\
\text { recursos... }\end{array}$ & & & $56 \%$ \\
\hline
\end{tabular}

Jornadas de Formación e Innovación Docente del Profesorado | № 2 (2019) Esta obra se distribuye con la licencia Creative Commons Reconocimiento-NoComercial-SinObraDerivada Internacional (CC BY-NC-ND 4.0.) 
Tabla 8. Estrategias de las Empresas Transnacionales para salir de la crisis (Globalización)

\begin{tabular}{|l|c|l|c|}
\hline \multicolumn{1}{|c|}{ Respuestas } & $\begin{array}{c}\text { Cuestionario } \\
\text { inicial }\end{array}$ & \multicolumn{1}{|c|}{$\begin{array}{c}\text { Principales } \\
\text { obstáculos }\end{array}$} & $\begin{array}{c}\text { Cuestionario } \\
\text { final }\end{array}$ \\
\hline No sabe/no contesta & $51 \%$ & & $0 \%$ \\
\hline Deslocalización, filiales.. & $30 \%$ & $\begin{array}{l}\text { Ideas generales/ } \\
\text { medios de } \\
\text { comunicación } \\
\text { masas } \\
\text { (producción en } \\
\text { China..) }\end{array}$ & $0 \%$ \\
\hline $\begin{array}{l}\text { Otros: internet, } \\
\text { publicidad, márketing... }\end{array}$ & $19 \%$ & & $5 \%$ \\
\hline $\begin{array}{l}\text { Empresa Red } \\
\text { (externalización, } \\
\text { subcontratación...) }\end{array}$ & $0 \%$ & & $24 \%$ \\
\hline $\begin{array}{l}\text { Conjunto de estrategias } \\
\text { económicas: Red, F\&A, } \\
\text { Financiarización }\end{array}$ & $0 \%$ & & $71 \%$ \\
\hline
\end{tabular}

Tabla 9. ¿Qué es el Pico del Petróleo?

\begin{tabular}{|l|c|l|c|}
\hline \multicolumn{1}{|c|}{ Respuestas } & $\begin{array}{c}\text { Cuestionario } \\
\text { inicial }\end{array}$ & \multicolumn{1}{|c|}{$\begin{array}{c}\text { Principales } \\
\text { obstáculos }\end{array}$} & $\begin{array}{c}\text { Cuestionario } \\
\text { final }\end{array}$ \\
\hline No sabe/no contesta & $71 \%$ & & $0 \%$ \\
\hline $\begin{array}{l}\text { Agotamiento del } \\
\text { petróleo }\end{array}$ & $7 \%$ & $\begin{array}{l}\text { Ideas generales/ } \\
\text { medios de } \\
\text { comunicación masas } \\
\text { (producción en } \\
\text { China..) }\end{array}$ & $8 \%$ \\
\hline $\begin{array}{l}\text { Otras: extracción } \\
\text { máxima, altos } \\
\text { precios.. }\end{array}$ & $20 \%$ & & $0 \%$ \\
\hline $\begin{array}{l}\text { Definición correcta } \\
\text { e implicaciones } \\
\text { socioeconómicas }\end{array}$ & $2 \%$ & & $93 \%$ \\
\hline
\end{tabular}

Jornadas de Formación e Innovación Docente del Profesorado | № 2 (2019) Esta obra se distribuye con la licencia Creative Commons Reconocimiento-NoComercial-SinObraDerivada Internacional (CC BY-NC-ND 4.0.) 
Tabla 10.¿Consideras que el "libre comercio" tal y como se considera convencionalmente en la actualidad es un obstáculo para el desarrollo de la mayor parte de los paises?

\begin{tabular}{|l|c|l|c|}
\hline \multicolumn{1}{|c|}{ Respuestas } & $\begin{array}{c}\text { Cuestionario } \\
\text { inicial }\end{array}$ & Principales obstáculos & $\begin{array}{c}\text { Cuestionario } \\
\text { final }\end{array}$ \\
\hline $\begin{array}{l}\text { No sabe/no } \\
\text { contesta }\end{array}$ & $13 \%$ & $\begin{array}{l}\text { No tienen muy claro } \\
\text { en qué consiste el } \\
\text { “libre comercio" }\end{array}$ & $0 \%$ \\
\hline $\begin{array}{l}\text { Sí es un obstáculo } \\
\text { (no aporta } \\
\text { argumentos) }\end{array}$ & $40 \%$ & $\begin{array}{l}\text { Han leído algunas } \\
\text { lecturas pero carecen } \\
\text { de argumentos }\end{array}$ & $0 \%$ \\
\hline $\begin{array}{l}\text { Si, destruye a } \\
\text { los productores } \\
\text { locales }\end{array}$ & $30 \%$ & $\begin{array}{l}\text { Idea convencional } \\
\text { (teoría del Libre } \\
\text { Comercio) }\end{array}$ & $0 \%$ \\
\hline $\begin{array}{l}\text { No es un } \\
\text { obstáculo } \\
\text { (no aporta } \\
\text { argumentos) }\end{array}$ & $17 \%$ & & $97 \%$ \\
\hline $\begin{array}{l}\text { Si, relaciones } \\
\text { asimétricas } \\
\text { (reglas, poder } \\
\text { económico...) }\end{array}$ & $0 \%$ & & \\
\hline
\end{tabular}

Como puede apreciarse, el impacto del método docente aplicado ha sido muy significativo. Lo más extraordinario, quizás, ha sido que, con dicho método, los estudiantes han sido capaces de interrelacionar todos los "temas" y los conceptos trabajados. En un cuestionario sobre la docencia que se pasó a l@s alumn@s a final de curso, el cien por cien de los mismos pudo desarrollar el hilo conceptual de la asignatura y de todas y cada una de sus partes de manera relacionada.

A continuación (Tabla 11) se realiza una valoración global por parte de la docente del CMD aplicado durante este curso académico y algunas propuestas de mejora para el próximo curso. 


\section{CAROLINA MÁrquez GUERRERo}

Tabla 11. Una valoración global del CMD aplicado y propuestas de mejora

\begin{tabular}{|c|c|c|c|}
\hline & LO QUE MEJOR HA FUNCIONADO & LO QUE FUNCIONÓ MENOS & PROPUESTAS PARA EL FUTURO \\
\hline \multirow{2}{*}{$\begin{array}{l}\text { n } \\
\text { 竞 } \\
\text { 은 }\end{array}$} & $\begin{array}{l}\text { Se han reducido drásticamente los } \\
\text { contenidos (no los temas ni los } \\
\text { problemas principales a estudiar) } \\
\text { Los alumnos pidieron incluir el estudio } \\
\text { de Alternativas socioeconómicas al } \\
\text { modelo actual (demasiado "pesimismo") }\end{array}$ & $\begin{array}{l}\text { El temario sigue siendo muy largo si } \\
\text { se quiere trabajar con profundidad y a } \\
\text { un ritmo que permita a los estudiantes } \\
\text { asimilar los contenidos fundamentales. }\end{array}$ & $\begin{array}{l}\text { Reestructurar el programa } \\
\text { incluyendo las propuestas de } \\
\text { l@s alumn@s }\end{array}$ \\
\hline & $\begin{array}{l}\text { Se ha ido desde lo concreto hacia lo } \\
\text { abstracto. El conocimiento abstracto o } \\
\text { es el resultado del propio proceso de } \\
\text { aprendizaje del alumno o no lo es. } \\
\text { Me he dado cuenta de que no es } \\
\text { imprescindible que yo lo explique todo } \\
\text { y que es más eficaz que ellos lleguen a } \\
\text { sus propias conclusiones a partir de la } \\
\text { información suministraada y trabajada }\end{array}$ & & $\begin{array}{l}\text { El objetivo es: aportar "ideas } \\
\text { ruptura"; plantear preguntas, } \\
\text { abrir debates, cuestionar ideas } \\
\text { establecidas y no "dar un } \\
\text { conocimiento cerrado" lo que no } \\
\text { es posible ni deseable. }\end{array}$ \\
\hline
\end{tabular}

Jornadas de Formación e Innovación Docente del Profesorado I № 2 (2019) 


\section{CAROLINA MÁrquez GUERRERo}

\begin{tabular}{|c|c|c|c|}
\hline \multirow[t]{2}{*}{$\begin{array}{l}\text { 웜 } \\
\text { 옹 } \\
\text { 을 }\end{array}$} & $\begin{array}{l}\text { Cuestionarios iniciales: una herramienta } \\
\text { muy útil a la hora de planificar y llevar } \\
\text { a cabo actividades de contraste. } \\
\text { Permite "dirigir" el proceso de } \\
\text { aprendizaje de una manera directa } \\
\text { hacia los principales obstáculos } \\
\text { mentales de los estudiantes. Eficacia. } \\
\text { Gran receptividad por parte de los } \\
\text { estudiantes porque lo que se explica/ } \\
\text { trabaja está directamente vinculado con } \\
\text { lo que piensan y les preocupa } \\
\text { Compartir las respuestas de los } \\
\text { cuestionarios iniciales con los alumnos. } \\
\text { Curiosidad por conocer qué piensan } \\
\text { otros compañeros. Les abre la puerta a } \\
\text { nuevos conocimientos/ideas. Despierta } \\
\text { el interés. }\end{array}$ & $\begin{array}{l}\text { Preguntas a veces no muy claras o } \\
\text { repetitivas. Preguntas indirectas que no } \\
\text { van a la raíz de los problemas }\end{array}$ & $\begin{array}{l}\text { Revisar los cuestionarios y pulir } \\
\text { los mapas conceptuales }\end{array}$ \\
\hline & $\begin{array}{l}\text { Debates en clase (grupo grande). Gran } \\
\text { avance en este punto! Este era uno de } \\
\text { mis principales obstáculos de mi primer } \\
\text { CMD. Es una de las dos actividades que } \\
\text { más les ha gustado del curso. } \\
\text { Imprescindible las lecturas previas } \\
\text { realizadas en casa para poder debatir. }\end{array}$ & $\begin{array}{l}\text { Muchos alumnos siguen sin participar } \\
\text { a pesar de haber hecho las lecturas } \\
\text { correspondientes y de "tener ganas de } \\
\text { hablar". Miedo a no pensar como la } \\
\text { profesora, timidez... }\end{array}$ & $\begin{array}{l}\text { Fomentar el trabajo en equipo } \\
\text { (grupos pequeños) donde } \\
\text { l@s alumn@s se sientan más } \\
\text { cómodos para poder participar. }\end{array}$ \\
\hline
\end{tabular}

Jornadas de Formación e Innovación Docente del Profesorado I № 2 (2019)

(C) (i) $\Theta\left(\begin{array}{l}\text { Esta obra se distribuye con la licencia Creative Commons } \\ \text { Reconocimiento-NoComercial-SinObraDerivada } \\ \text { Internacional (CC BY-NC-ND 4.0.) }\end{array}\right.$




\section{CAROLINA MÁRQUEZ GUERRERO}

\begin{tabular}{|c|c|c|}
\hline $\begin{array}{l}\text { Debates organizados en grandes grupos } \\
\text { buscando la polarización de enfoques } \\
\text { o puntos de vista. Los alumnos se veían } \\
\text { obligados a buscar argumentos y a } \\
\text { debatir con los compañeros de los otros } \\
\text { grupos. Les ha gustado mucho esta } \\
\text { actividad }\end{array}$ & $\begin{array}{l}\text { Se han hecho muy pocos debates de este } \\
\text { tipo. Preocupación por la falta de tiempo }\end{array}$ & $\begin{array}{l}\text { Incluir algún debate más de este } \\
\text { tipo }\end{array}$ \\
\hline & $\begin{array}{l}\text { Trabajos y debates en grupos pequeños } \\
\text { (4-5): no han funcionado tan bien } \\
\text { aunque se programaron para facilitar la } \\
\text { intervención/participación de tod@s. } \\
\text { La “autogestión" no ha funcionado } \\
\text { demasido bien, quizás por falta de } \\
\text { constumbre por parte de l@s alumn@s y } \\
\text { también por una deficiente organización } \\
\text { por parte de la profesora }\end{array}$ & $\begin{array}{l}\text { Organizar y preparar mejor } \\
\text { los trabajos en grupo para } \\
\text { que los alumnos tengan más } \\
\text { claro lo que tienen que hacer } \\
\text { y se impliquen más, y lo } \\
\text { hagan de manera simétrica y } \\
\text { equilibrada (p.e. pidiendoles } \\
\text { que lo expongan en clase en 10'; } \\
\text { evaluándose entre ellos mismos, } \\
\text { etc..) }\end{array}$ \\
\hline $\begin{array}{l}\text { Clases "magistrales": cada vez más } \\
\text { puntuales, estratégicas, y eficaces; } \\
\text { dirigidas a cubrir los aspectos que } \\
\text { no pueden trabajarse de manera tan } \\
\text { sintética y eficaz con otro tipo de } \\
\text { actividades (lecturas, videos, etc..) }\end{array}$ & & Seguir en la misma línea \\
\hline $\begin{array}{l}\text { Exposiciones por parte de los alumnos } \\
\text { de trabajos de "investigación" (Los } \\
\text { alumnos han trabajado el tema de las } \\
\text { Alternativas con gran satisfacción) }\end{array}$ & $\begin{array}{l}\text { No estaban planificadas en el CMD; se } \\
\text { han incorporado al final a demanda de } \\
\text { los alumnos }\end{array}$ & $\begin{array}{l}\text { Incluirlas desde el principio } \\
\text { dando opción a los alumnos a } \\
\text { participar en el tema que ellos } \\
\text { quieran }\end{array}$ \\
\hline
\end{tabular}

Jornadas de Formación e Innovación Docente del Profesorado I № 2 (2019)

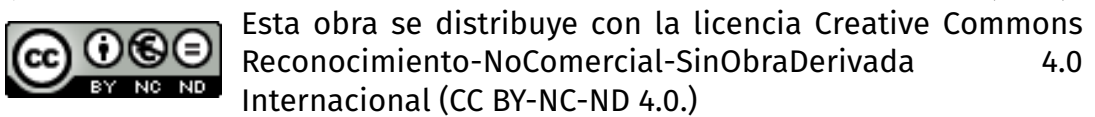




\section{CAROLINA MÁRQUEZ GUERRERO}

\begin{tabular}{|c|c|c|}
\hline & Videos: algunos demasiado largos & $\begin{array}{l}\text { Recortar los videos } \\
\text { seleccionando los espacios } \\
\text { estrictamente necesarios }\end{array}$ \\
\hline $\begin{array}{l}\text { Cuestionarios finales: una herramienta } \\
\text { utilisima para que los alumnos } \\
\text { puedan cerrar el "tema": sintetizar, } \\
\text { interrelacionar, reflexionar y consolidar } \\
\text { conceptos, etc.. } \\
\text { Muy valorado por todos los alumnos }\end{array}$ & $\begin{array}{l}\text { Al principio se lo toman como una } \\
\text { actividad más o menos mecánica con } \\
\text { lo que se pierde una de las fases más } \\
\text { importantes del proceso de aprendizaje }\end{array}$ & $\begin{array}{l}\text { Hay que explicar muy bien } \\
\text { desde el principio el sentido } \\
\text { y la funcionalidad de los } \\
\text { cuestionarios. No se trata sólo } \\
\text { de una herramienta para la } \\
\text { evaluación. Su función es mucho } \\
\text { más importante }\end{array}$ \\
\hline $\begin{array}{l}\text { Con cada cuestionario final se pedía } \\
\text { a los alumnos que evaluaran de } 0 \\
\text { a } 5 \text { cada una de las actividades de } \\
\text { contraste realizadas en ese tema: video, } \\
\text { lecturas, explicación de la profesora, } \\
\text { trabajo en equipo, debates, etc... }\end{array}$ & & $\begin{array}{l}\text { Estupenda información para } \\
\text { programar las actividades de } \\
\text { contraste para el próximo curso. } \\
\text { Continuar con este cuestionario } \\
\text { el curso que viene }\end{array}$ \\
\hline $\begin{array}{l}\text { Mapas conceptuales: una herramienta } \\
\text { muy útil para diseñar y organizar } \\
\text { el proceso “investigativo" de los } \\
\text { estudiantes } \\
\text { Mapas conceptuales como árboles de } \\
\text { preguntas que se ramifican permitiendo } \\
\text { un conocimiento cada vez más } \\
\text { profundo }\end{array}$ & $\begin{array}{l}\text { No he compartido los mapas } \\
\text { conceptuales con los estudiantes. No } \\
\text { siento que, por ahora, sea necesario. } \\
\text { Pensé que eso les iba a liar más que } \\
\text { aclararles. No se teoriza: de lo concreto } \\
\text { (que aporto yo) a lo general (que lo } \\
\text { extraen u obtienen ellos, o no lo extraen) }\end{array}$ & $\begin{array}{l}\text { Compartir con los alumnos los } \\
\text { mapas conceptuales en todo } \\
\text { caso al final del tema }\end{array}$ \\
\hline
\end{tabular}

Jornadas de Formación e Innovación Docente del Profesorado I № 2 (2019) 


\section{CAROLINA MÁrquez GUERRERo}

\begin{tabular}{|c|c|}
\hline $\begin{array}{l}\text { Imprescindible una organización } \\
\text { exhaustiva de la secuencia de } \\
\text { actividades y una programación } \\
\text { detallada de las mismas; esto no es } \\
\text { incompatible con la flexibilidad sino } \\
\text { todo lo contrario. Cada actividad tiene } \\
\text { un objetivo muy concreto y cada } \\
\text { objetivo tiene una o varias actividades. }\end{array}$ & Seguir en la misma línea \\
\hline $\begin{array}{l}\text { Papel cada vez más importante de los } \\
\text { estudiantes. Antes lo vivía con cierto } \\
\text { miedo (riesgo a su participación real) } \\
\text { pero ahora no concibo volver al modelo } \\
\text { antiguo. Por ejemplo, he sentido que no } \\
\text { podía iniciar un nuevo "tema" sin haber } \\
\text { leído previamente los cuestionarios } \\
\text { iniciales; me sentía insegura, } \\
\text { desorientada y no sabía muy bien como } \\
\text { enfocar el proceso. clases mucho más } \\
\text { fluídas, cómodas, interesantes, "soltada } \\
\text { de manos" (antes me daba pánico que } \\
\text { el cañón no funcionara y no pudiera } \\
\text { poner mis powerpoint). Los estudiantes } \\
\text { han dejado de ser un "grupo anónimo"; } \\
\text { el monólogo está dejando paso a una } \\
\text { enseñanza cada vez más interactiva y } \\
\text { centrada en los propios estudiantes. } \\
\text { Un aprendizaje desde, por y para los } \\
\text { estudiantes. }\end{array}$ & $\begin{array}{l}\text { Seguir en esta línea incidiendo } \\
\text { en "dar clases con la boca } \\
\text { cerrada" }\end{array}$ \\
\hline
\end{tabular}

Jornadas de Formación e Innovación Docente del Profesorado I № 2 (2019)

(C) $\left(\right.$ ) $\Theta\left(\begin{array}{l}\text { Esta obra se distribuye con la licencia Creative Commons } \\ \text { Reconocimiento-NoComercial-SinObraDerivada }\end{array}\right.$
Internacional (CC BY-NC-ND 4.0.)




\begin{tabular}{|c|c|c|c|}
\hline & $\begin{array}{l}\text { Menor preocupación por parte de la } \\
\text { profesora por "cerrar" los temas y } \\
\text { formular las conclusiones }\end{array}$ & & $\begin{array}{l}\text { El objetivo es formular } \\
\text { preguntas, crear dudas y abrir } \\
\text { caminos de indagación. "Soltar" } \\
\text { más por mi parte }\end{array}$ \\
\hline \multirow[t]{2}{*}{ 芑 } & $\begin{array}{l}\text { Ha habido muchos ítems para evaluar: } \\
\text { tareas individuales, trabajos en equipo, } \\
\text { cuestionarios. } \\
\text { He podido valorar realmente lo que } \\
\text { han aprendido l@s alumn@s. Con } \\
\text { el examen final no podía saberlo } \\
\text { de ningún modo (repetición de los } \\
\text { apuntes con mayor o menor precisión y } \\
\text { comprensión) } \\
\text { Los alumnos han valorado muy } \\
\text { positivamente este sistema de } \\
\text { "evaluación continua real" }\end{array}$ & $\begin{array}{l}\text { Tarea extraordinariamente costosa la de } \\
\text { evaluar todas las actividades (lecturas, } \\
\text { trabajos en grupo, cuestionarios } \\
\text { finales...). En este CMD se han evaluado } \\
16 \text { actividades para } 136 \text { alumnos. } \\
\text { No siento que este método sea } \\
\text { sostenible }\end{array}$ & $\begin{array}{l}\text { En el cuestionario final } \\
\text { entregado a los alumnos, los } \\
\text { mismos reconocen que si no } \\
\text { se evaluaran las tareas, la } \\
\text { mayoría no las realizarían. Creo } \\
\text { que es imprescindible que los } \\
\text { alumnos realicen las tareas de } \\
\text { casa si se quiere seguir este } \\
\text { método. ¿Algún sistema de } \\
\text { autoevaluación para alguna } \\
\text { tarea? }\end{array}$ \\
\hline & & $\begin{array}{l}\text { No ha habido feed-back individual. } \\
\text { Me hubiera encantado poder hacerlo } \\
\text { y tenía todo lo necesario para hacerlo } \\
\text { (numerosas tareas por escrito y } \\
\text { cuestionarios), pero no ha habido tiempo } \\
\text { material. El feed-back individual se } \\
\text { ha limitado a las revisiones que los } \\
\text { alumnos han solicitado de sus tareas y } \\
\text { cuestionarios. }\end{array}$ & $\begin{array}{l}\text { No veo que sea posible en las } \\
\text { condiciones actuales de la } \\
\text { docencia concentrada en el } \\
\text { semestre ( } 16 \text { horas/semana } \\
\text { de media), } 100 \text { alumn@s que } \\
\text { siguen la evaluación continua }\end{array}$ \\
\hline
\end{tabular}




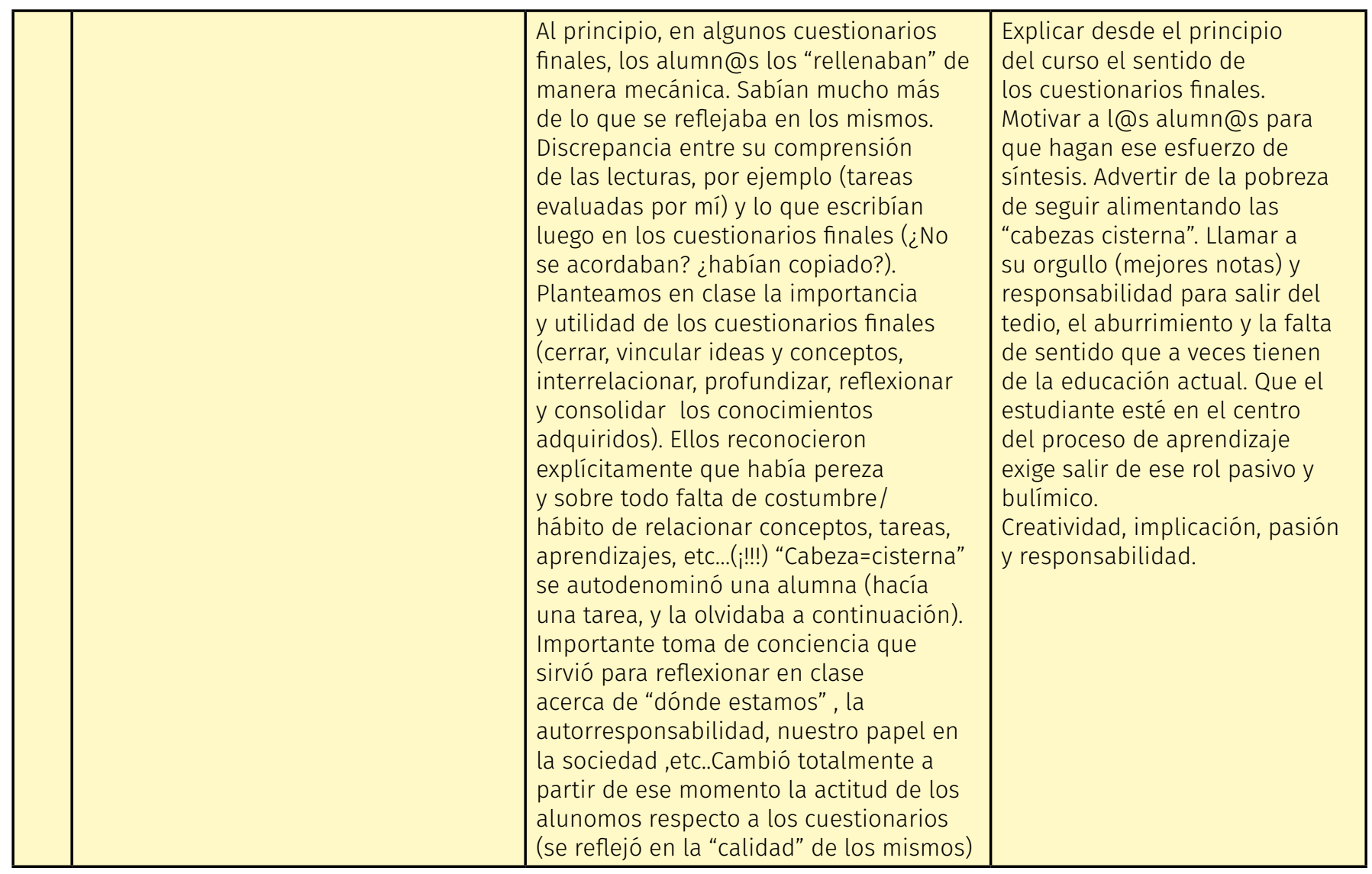




\section{CAROLINA MÁRQUEZ GUERRERO}

\begin{tabular}{|l|l|l|l|}
\hline & $\begin{array}{l}\text { No he evaluado a partir de las escaleras } \\
\text { de aprendizaje. La evaluación de los } \\
\text { cuestionarios finales ha sido una } \\
\text { evaluación “convencional"; es decir se } \\
\text { califica de 0 a 10, aunque teniendo en } \\
\text { cuenta lo que se había escrito en el } \\
\text { cuestionario inicial. }\end{array}$ & $\begin{array}{l}\text { Veo factible la elaboración } \\
\text { de lascaleras de aprendizaje } \\
\text { como instrumento de evaluación } \\
\text { de los alumnos. Seleccionar } \\
\text { grupo de estudio para evaluar la } \\
\text { docencia }\end{array}$ \\
\hline & $\begin{array}{l}\text { Seguimiento del diario de la profesora: } \\
\text { empecé muy bien pero tuve que } \\
\text { abandonarlo, fundamentalmente por } \\
\text { falta de tiempo. Sobre un documento } \\
\text { impreso en el que aparecía todo el CMD } \\
\text { (mapas, cuestionarios y actividades } \\
\text { programadas) he podido ir anotando } \\
\text { los cambios introducidos, propuestas, } \\
\text { etc...He sido incapaz de llevar un diario, } \\
\text { pero lo más relevante ha sido anotado y } \\
\text { tenido en cuenta. }\end{array}$ & $\begin{array}{l}\text { Mán partir de mi propuestade CMD. } \\
\text { capararme un cuaderno para } \\
\text { cada grupo (son 3) e ir anotando } \\
\text { los cambios, incidencias, etc.. } \\
\text { sobre la base de las actitivades } \\
\text { programadas, y no en función } \\
\text { del tiempo (diario) }\end{array}$ \\
\hline
\end{tabular}

Jornadas de Formación e Innovación Docente del Profesorado I № 2 (2019) 


\section{Referencias:}

Bain, K. (2007) Lo que hacen los mejores profesores de la universidad, PUV, Publicacions de la Universitat de Valencia

Finkel, D. (2008) Dar clase con la boca cerrada, Universitat de Valencia

Müller, T. y Schmalenbach, Ch. (2016) “Escaleras de aprendizaje: enseñando con la metodología multigradomultinivel", Ed. Univesidad Don Bosco, ano 10, no18, pp. 47-56

Naredo, J.M. Raíces económicas del deterioro ecológico y social, s.XXI

Porlán, R. et.al (2017) Enseñanza universitaria, cómo mejorarla, Ed. Morata

Trainer, T. (2017) La vía de la simplicidad, Ed. Trott

Jornadas de Formación e Innovación Docente del Profesorado | № 2 (2019) Esta obra se distribuye con la licencia Creative Commons 